\title{
Globalization Impacts on Chinese Politics and Urbanization
}

\author{
Jamie P. Halsall ${ }^{1}$, Ian G. Cook ${ }^{2}$ \\ ${ }^{1}$ School of Human and Health Sciences, The University of Huddersfield, Huddersfield, UK \\ ${ }^{2}$ School of Humanities and Social Science, Liverpool John Moores University, Liverpool, UK \\ Email: j.p.halsall@hud.ac.uk, i.g.cook@ljmu.ac.uk
}

Received December 29 $9^{\text {th }}$, 2012; revised February 22 ${ }^{\text {nd }}$, 2013; accepted March $4^{\text {th }}, 2013$

\begin{abstract}
Copyright ( 2013 Jamie P. Halsall, Ian G. Cook. This is an open access article distributed under the Creative Commons Attribution License, which permits unrestricted use, distribution, and reproduction in any medium, provided the original work is properly cited.
\end{abstract}

\begin{abstract}
The aim of this paper is to critically explore the complex debates on the contemporary growth of China's urban economies. It has been well documented that China is the second largest economy in the world and is seen to be a major player in the financial markets. Over the last decade China has experienced a dramatic urban transformation and globalization is a key factor in the change in China from Maoist production cities to Dengist cities of consumption, albeit with a strong export-oriented production element. As this paper will argue, without the impact of Globalization, the recent development of China as a key economic power could not have taken place. The findings of this research revealed however, that the Chinese State has also played a key role, intertwined as it is with the Chinese Communist Party (CCP).
\end{abstract}

Keywords: China; Cities; Globalization; Urbanization

\section{Introduction}

"Globalization may well be an ancient theme but it is also one that evolves; and that capacity to progress explains why it has become the dominant motif of the contemporary world" (Williams, 2012: p. 27).

Globalization has become the term of the moment. Over the last 20 years the social science discipline has been fascinated by the processes of globalization within a given society (Sapkota, 2011; Gaulier, 2007; Guillaume et al., 2007; Kirby, 2006; Temin, 1999). The key functions that formulate the powers of globalization are conceptualized into four distinct processes: 1) economic; 2) political; 3) social; and 4) cultural. However, scholars have become critical on the theorizing and the development of globalization. Recent literature has demonstrated that globalization is a deeply contested concept that has no clear definition. For example Held et al., (2002) have argued that that globalization lacks a precise definition. Whilst Munck (2002: p. 52) has expressed the view that globalization can mean "everything and anything, or nothing” and Dicken (2004: p. 5) has portrayed globalization as a "big problem in every sense of the term”. Overall it could be argued that globalization has created a sense of slippage and danger. Slippage in the sense that the concept can have different meanings and therefore can be interpreted in many different ways and danger for the reason that globalization is a powerful concept that affects everyone around the globe, thus impacting on developed and developing countries.

The theorization of the debates surrounding globalization and Chinese urbanization has been well documented (Wang et al., 2012; Wu \& Gaubatz, 2012; Wu \& Webster, 2010; Zhang, 2008; Zhao et al., 2003; Yusuf \& Wu, 2002). Hence, the aim of this paper is to critically discuss the current globalization and urbanization debates within the context of China. This article is divided into three parts. The paper firstly seeks to examine the theoretical controversy on globalization. The following section discusses the political structure of China from an economic globalization perspective. Finally, the paper examines the impact of urbanization in China.

\section{Globalization}

Since the millennium globalization has gained a "global currency circulating through complex networks formed by multilateral institutions, broadcast, print and electronic media, academic exchange and the self-reflexive analysis” (Kelly, 1999: p. 380). Guttal (2007: p. 523) has noted that:

“The term 'globalization' is widely used to describe a variety of economic, cultural, social, and political changes that have shaped the world over the past 50-old years, from the much celebrated revolution in information technology to the diminishing of national and geo-political boundaries in an ever-expanding, transnational movement of goods, services, and capital. The increasing homogenisation of consumer tastes, the consolidation and expansion of corporate power, sharp increases in wealth and poverty, the 'McDonaldisation' of food and culture, and the growing ubiquity of liberal democratic ideas are all, in one way or another, attributed to globalization.”

This new formulation of economic, political, social and cultural processes has creating a new importance of the theorizing of globalization. Held et al., (2002) have argued that these new developments have modernized the globalization schools of thought. The schools of thought in Held et al., (2002) are comprised of three theses: 1) Hyberglobalist; 2) Sceptic; and 3) Transformationalist. Hyberglobalist hold the view that globalization has brought about a "denationalization" of economies. 
Sceptics believe that globalization is a "myth" and therefore sceptics rely on an economist conception of globalization. The transformationalist thesis believes that globalization is a central driving force behind the social, political and economic change that is reshaping modern societies. It therefore could be argued that China's economic fortunes since 1978 is a transformationalist approach as Holscher et al., (2010: p. 214) notes economic reform has developed "evolution from an inefficient planned economy begun in 1978 and the trajectory of economic reforms".

\section{The Political Structure of China}

Unlike most States in the world today, the People's Republic of China (PRC) is dominated by a single Party, the Chinese Communist Party (CCP). To the casual observer the CCP seems to be a hierarchical structure, in which dissent from top decisions is not tolerated. However, although decisions once agreed must indeed be adhered to, within the CCP there are conflicting views that are discussed prior to this decision making, and there are structures within both the party and the government apparatus which are difficult to unravel, in that the body which often seems to be the locus of power is not necessarily so, while the posts which individuals hold may or may not be indicative of their position in the power hierarchy. China after all is a vast country; the CCP is a vast organization, comprising more than seventy-eight million members (as of end 2009); it is surely hardly surprising, therefore, that internal differences exist within this entity. What may be more surprising, however, is that these differences can cut across logical lines, such as age, locality of origin, or ideological leaning. Writing some years ago Parker expressed the situation as "For westerners, the crucial fact about Chinese politics is that no-one understands them” (Parker, 1987: p. 20). We may strive to understand this internal complexity therefore, but need to recognise that a wide range of factors affect CCP and PRC decision-making.

These factors include, inter alia, the history of the CCP, both in terms of its internal development, and also the external influences upon it, legacies of this history including the Long March, the different generations of Party cadres that have been in power since the PRC was founded in 1949, the diverse personalities of CCP leaders, especially Mao Zedong and Deng Xiaoping, who have come to dominate at different time periods, and the relationship between the CCP, government structures and the bureaucracy of a highly centralized state apparatus. For example, schismatic tendencies arising from its historical development include differential propensities to revolutionary ideas exhibited in the contrasting locations where the party evolved, such as Shanghai for example, where, perhaps due to the stark inequalities which were found there in the inter-war era, developed a particularly strong revolutionary consciousness. In contrast, in the South of China there are often grumbles that few local cadres are promoted to the top jobs in Beijing, and the "emperor" would in that sense still seem to be "over the hills and far away" as the old saw it. At times, therefore "splitism" within the CCP has a regional element, as members from the same area come together and may even coalesce into factions.

Factions are likely to transcend such localism, however. A favorite word in China is guanxi, which can be translated as "connections", "networks", "reciprocal relationships", "who you know rather than what you know" taken together, and in a country of 1300 million plus people such connections are highly important. Guanxi might operate via localism, but it can also operate within universities, within government departments, via chance contacts, and via patronage, via ideological leanings, in an unceasing process of network building which cuts across age, background and class, to an extent. Politics in China, therefore, are often not simply left-right, or modernisers-conservatives; they are more complex than that. There may be for example "Reformers", "Adjusters" and "Conservers" within the party (Sollinger, 1993: p. 31), and although as Zhao Ziyang once put it, there is "only one faction, the Marxists", schismatic tendencies are found, and these are extremely difficult to unravel. Finally, there is also fluidity in these alliances and groups, so that coalescence or some fragmentation may take place, depending on the issues of the day, and the power which the faction can exert.

Then there are the formal structures, of both the Party and the State. Although there are eight "democratic parties" in China, it is the other party, the CPC which holds power:

"The Chinese Communist Party is the leading organ in society. It sees itself as the vanguard of the proletariat and its role is to lay down policy, which the state then implements” (Mackeras \& Yorke, 1991: p. 59).

The highest body of the CCP is the "National Congress" which meets on a regular basis every few years. The Congress (of less than 2000 delegates of the full membership) elects the "Central Committee" (numbered as per the Congress which elects it, and currently of less than 200 full members, plus alternates) which meets in a (numbered) "plenum", on a roughly annual basis. Thus one could have the 6th plenum of the 13th Central Committee of the (13th) National Congress, for example. The Central Committee in turn elects the "Political Bureau" ("Politburo") currently of 20 members and the "Standing Committee of the Politburo", currently of 7 members. There is also a secretariat, but "In reality, power lies within the Political Bureau (Politburo), its Standing Committee, and, to a lesser extent within the Secretariat” (Saich, 1995: p. 41). Other powerful bodies are the "Military Commission" and the "Central Commission for Discipline Inspection", with the former supervising the organizational links between the CCP and the PLA, and the latter responsible for checking opposition to policies, corruption and other abuses within the Party.

Parallel to this hierarchical structure, run via "democratic centralism" are the organizations of the State. The "National People's Congress" (NPC) is elected every five years and consists of several thousand members. It passes legislation and is now meeting annually. It elects the "President", currently $\mathrm{Hu}$ Jintao, the "Standing Committee" and the "Central Military Commission", and elects or decides on recommendations for such posts as the Premier (equivalent to the British Prime Minister), now Wen Jiabao, elected in 2003. The Standing Committee has legislative power on behalf of the National People's Congress, while the "State Council" is the "executive organ" of the NPC. Major cities-Beijing, Chongqing, Shanghai and Tianjin-are run directly via the State Council, which thus takes account of national needs and desires, not just or not even the needs and desires of these cities themselves. Thus Shanghai's economic development was restricted during the 1980s because the city had to provide a higher rate of taxation to Central Government, a policy that was eventually rescinded in 
Shanghai's favour in the 1990s.

It was Deng Xiaoping who famously led the drive towards the Open Door Policy along with the Four Modernizations that transformed China generally, and China's urban economies specifically. Following on from the political disaster of 1989 (Tiananmen), Deng's famous South China tour, under armed guard and at the advanced age of 88 years, gave the green light once more to the economic reform policies, and meant that from 1992 especially China's cities would be transformed (Cook, 1996; Cook \& Murray, 2001). An important element of this was that his tour ensured that not only would the reform process be reinforced but that "it could never be reversed" (Sanders, 2007: p. 2). The CCP had a key role in this process, as Deng's immediate successor Jiang Zemin noted:

"The CCP continued to be the key to the success of China's reform. As long as the CCP represents advanced forces of production, advanced culture, and the interests of the people, it can overcome all difficulties and continue to prevail. Jiang implied that with its "new blood", the CCP should be able to provide leadership and vision at a time of unprecedented technological revolution and economic globalization” (Li Cheng, 2001: p. 84).

Jiang's modernizing influence, therefore, was focused on the CPC itself, and he and others were influenced by Anthony Giddens book, The Third Way, which sought to reposition the UK's Labour Party of Tony Blair as a centrist rather than socialist project. There was even one call for the CCP to be renamed the Chinese Social Democratic Party (Giddens, 1998, p. 85). This would be a step too far, at least for the near future, but there is a strong drive to reenergise the CPC via a new generation of leaders, the fourth or even fifth generation, including intellectuals with foreign experience, entrepreneurs and technocrats. The new generation of leaders led by Hu Jintao seem to be more open to discussion of questions of poverty and inequalities, although they still seem to take a similarly hard line to Taiwan, for instance, as have previous CCP leaders. These leaders are far more aware of the global dimension of economic and political affairs, and it was as Vice-President in 2001 that Hu Jintao called upon Chinese enterprises to "go global" a call that has brought accelerated response since 2003 (Clegg, 2009: p. 138).

\section{Chinese Urbanization}

The impact of urbanization in China has been propelled by state policy. Lin (2002) has noted that when analyzing China's urbanization there are four distinct phases of expansion: 1) initial growth of cities and urbanization (1949-1961); 2) reduction of cities and de-urbanization (1962-1965); 3) stagnation and under-urbanization (1966-1977); and 4) accelerated growth and rapid urbanization (1978 to present). The fourth expansion has come about due to the impact of globalization within the context of China's economic reforms. According to Wu (2001: p. 286) economic reforms in China have enabled local government to promote local economic growth. Hence, local authorities have the power to control an increased proportion of resources and "As a result, urban policies have been re-oriented towards pro-business development in a similar to those observed in the West” (Wu, 2001: p. 286).

China for a long period of time has been perceived as an economic superpower. The United States National Intelligence
(2012) Report has predicted that by "2030 China is likely to have the world's largest economy” (Jia, 2012: p. 13). With this economic super power China's urbanization expansion has created new environmental and social challenges (Cook et al., 2013a). Longan (2008) has noted that the last two decades have created a culture of "haves" and "have nots" and that there is growing awareness of social inequalities. Zhang X. and Zhang K. H. (2003: p. 48) have noted that:

\begin{abstract}
"It is virtually certain for China to become even more important in the world economy in the future because of its huge size, dynamic economic growth, continuing policy reforms, and specially its recent entry of the world Trade Organization. Perhaps like other developing countries, China's economic integration with the world has been accompanied with growing regional inequality. Especially the income gap between coastal and inland areas has risen dramatically since the mid-1980s... Commentators in China have expressed concern about regional inequality and some even warned that further increases in regional disparities might lead to China's dissolution...”
\end{abstract}

It has been suggested by $\mathrm{Wu}$ (2007) that the reason why social inequality is seen to be problematic in urban China is directly linked to three major challenges: 1 ) deindustrialization (redundancy of state employment); 2) the change in the labour market and; 3) public policies (housing privatization and minimum income support).

The combination of the factors noted earlier in this paper meant that China's major cities such as Beijing or Shanghai have become international metropolises with thriving modern, possibly even postmodern, urban economies. As noted above, four of these cities-Beijing, Tianjin, Shanghai and Chongqing -are run directly by the Chinese State via the State Council. This means for example that megaprojects within such cities, including the Beijing Olympics of 2008, or the Shanghai Expo of 2010, can readily be subsidised by Central Government which can take a China-wide perspective and a direct controlling hand upon such international events. Economic growth in such cities is such that, as an example, by 2008, Beijing's GDP was 1.05 trillion yuan (exchange rate is 10 yuan to the $£$ at present) and the percentage of the primary industry, secondary industry and tertiary industry was $1.08,25.68$, and 73.24 while public green land per capita was 12.6 square meters, with a green coverage rate of $40 \%$ (Gu \& Cook, 2010). As these authors note:

"Today, Beijing is one of the most exciting and dynamic cities on earth. The transformation of Beijing from recently being a rather drab, dull and austere production city, albeit one with long historical roots, towards being a city of hi-tech manufacturing, service provision and mass consumption has been breathless in its speed and scope.”

Beijing moved from being a city that, under Mao Zedong, was focused on industrial production with a focus on heavy industries such as iron and steel production and petro-chemical works, to one that, under Deng Xiaoping and his successors developed a consumption ethos. The Reform Period began in 1978 and witnessed increasing criticisms of the emphasis on industrial development, with Dong (1985) arguing that the city was "poorly endowed for industrial development" (Dong, 1985, p. 73) and yet was "rich in cultural resources" the city therefore: 
"should concentrate on expanding its role as the nation's administrative centre. It should develop also as a centre of scientific research, education, cultural activities and tourism. A few industries should be permitted, but only those which do not consume large amounts of water or create pollution” (Dong, 1985: p. 75).

Such ideas gradually gained the upper hand, but Tiananmen in 1989 was a major setback, and it was not until 1992 following Deng's famous tour of South China in which he called for an acceleration of his "Open Door" programme (Cook \& Murray, 2001), that Beijing was set to become a modern commodity economy which combined planning guidelines and a market system. Investments began to flow in, initially from Hong Kong, Taiwan, and Overseas Chinese in Singapore, and then increasingly from Europe, the US and elsewhere. Hotels, offices, shopping malls, housing developments, and cultural and exhibition centres were built, but this construction drive has resulted in tension between new build and conservation of the ancient Hutong areas (Cook et al., 2013b).

In recent years, value added hi-tech manufacturing has become more significant (Wu, 2007: p. 18) for instance in Zhongguancun 中關村 Science Park, where Microsoft, Nokia and other such hi-tech companies are located in China's "Silicon Valley". One attraction for these companies is that highly skilled Chinese labour is available from the universities, but far cheaper than in California or Seattle (Cook, 2006). Such developments were coordinated under a new Beijing Master Plan that was drawn up by the State Council for the 1991-2010 period (Zhang, 1991). Foreign investment and international cooperation was crucial to fund the rapid growth that the plan envisaged. Zhongguancun was the first of a series of "special zones" that actually dates back as far as 1988 when Beijing New Technology Industrial Development Experimental Zone was established in the Haidian 海淀 district, to the North West of the city, where a number of China's key universities were found. Today, the scale of these developments is such that an amazing 60 percent of Beijing's GDP derives from here. This is due to there being over 7000 companies concentrated in the zone that are involved principally in the information processing, pharmaceutical research, and the medical sector, supported by the facilities and personnel of 68 universities and 230 independent research institutions, which fund and support 36\% of the entire nation's researchers (Gu \& Cook, 2011).

Breathtaking though the scale of these developments may be, a similar type of zone was also established at the opposite end of Beijing, in the South East. The Beijing Technological and Economic Development Area (BDA) is situated in the "e-town" of Yizhuang and was begun in 1992. The "e-town" element was launched by the Beijing Municipal Government in 2007 as part of a long-term strategy from 2005-2020. According to Gu \& Cook (2011: p. 115):

"The development of a number of industrial clusters has been vigorously promoted at BDA. These include an ICT industrial cluster (with Nokia), an electronic industrial cluster, a medical equipment industrial cluster, a biopharmaceutical industrial cluster (with Bayer) and an auto industrial cluster (with Mercedes-Benz-Daimler Chrysler). More than 2000 enterprises from thirty countries and regions all over the world have established themselves at BDA with total investments exceeding US \$15 billion dollars, over seventy percent of which are investments by foreign-invested enterprises."

In contrast to these examples of the expansion of technological and scientific zones, heading in the opposite direction, is the reduction of the Capital Iron and Steel Works (Shijingshan 石景山) which at one time in the early 1990s was the largest in China, with an output of 8.24 million tons (Gu \& Cook, 2011). Partly due to the need to reduce pollution at the Olympic Games of 2008, and partly due to moves towards resolution of the debates as to the appropriate emphasis for Beijing's urban economy, this plant is being gradually relocated out of the city over 5 years to Caofeidian, Tangshan City, Hebei Province. The replacement activity in the site will have a considerably different emphasis with the development of recreation centres, business exhibition and innovative industries including Cinema 4D Shijingshan Amusement Park, Long Yang seawater swimming pool, the International Sculpture Park, and Ground Floor Entertainment City. This new more recreational and cultural emphasis is also found in other parts of the city, including the recolonisation of the 798 Factory Complex (a gift to the city from East Germany in 1956) from 2002 by large numbers of artists, writers, musicians and others. As Gu and Cook (2011: p. 115-116) note:

\begin{abstract}
"Artists of all sorts began occupying the available spaces, the area was enlivened by the opening of the first bars and restaurants, and the former factory became a hotbed of ideas and culture. A modern Museum of Film was established in 2006 and the Belgian Ullen's Centre for Contemporary Art was set up in 2007 with over 6000 square meters of land for development. This new 'Artist Village' has quickly become known internationally as an avantgarde cultural centre.”
\end{abstract}

Such a cultural development is similar to those across the globe, in cities such as Vancouver, Liverpool and London for example. But the biggest cultural economic event in Beijing in recent years is of course the Olympics of 2008. As Cook (2007) notes, the city bid unsuccessfully for the Olympics in the early 1990s, but the successful bid of 2001 reflected the opening up of the city, including major infrastructural improvements since then, as well as a psychological distantiation from Tiananmen. As Cook notes, there were worries before the Games concerning a range of issues including human rights, air pollution, housing demolition and other matters. In the event, the Games were a huge success, although certain issues still remain (Cook \& Miles, 2011). International architects as well as the likes of Ai Weiwei who had lived in the US for a decade before returning to his home country of China combined to build stunning structures such as the Bird's Nest stadium or the National Aquatics Centre or "Water Cube" in the Olympic Village site that is now becoming a major tourist attraction. In a nutshell:

"The physical impact of the Games is clear in terms of the massive programme of building work and infrastructural improvements... [but there is]... a broader concern that the primary long-term impact of the Olympic Games is to redefine Beijing as a space for consumption so that the Olympic Green area in particular becomes a glitzy space for privatized public pleasures” (Cook \& Miles, 2011: p. 355). 


\section{Conclusion}

This paper has examined the complex relationship of globalization and the impact of this on Chinese urbanization. At the centre of this complex relationship are the political structure and the influence that the Chinese Communist Party (CCP) has on globalization and urbanization. In this paper the authors have argued that China's globalization school of thought is transformationalist due to the economic reform developed since 1978. However this impact of economic globalization within the context of urbanization in Chinese cities has brought scrutiny in terms of the impacts on society. The most notable change in society is the increasing levels of inequality in Chinese cities. One significant change is the level of urban investment and the fundamental impact that this has on cities it terms of education, employment and housing. However the most notable change in society is the increasing level of inequality in Chinese cities.

\section{REFERENCES}

Clegg, J. (2009). China's global strategy: Towards a multipolar world. London: Pluto Press.

Cook, I. G. (2006) Beijing as an "internationalized metropolis", Chapter 4. In F. Wu (Ed.), Globalisation and China's cities, London: Routledge.

Cook, I. G. (2007). Beijing 2008, Chapter 16. In J. R. Gold, \& M. M. Gold (Eds.), Olympic cities: City agendas, planning and the world's games, 1896-2012. Abingdon: Routledge Planning, History and Environment Series.

Cook, I. G., Gu, C., \& Halsall, J. P. (2013a). China’s low income urban housing. Asian Social Science, 9, 7-17. doi:10.5539/ass.v9n3p7

Cook, I. G., Gu, C., \& Halsall, J. P. (2013b). China’s growing urban health inequalities: The challenges ahead. Journal of Management and Sustainability, 3, 10-18. doi:10.5539/jms.v3n2p10

Cook, I. G., \& Miles, S. (2011). Beijing 2008, Chapter 17. In J. R. Gold, \& M. M. Gold (Eds.), Olympic cities: City agendas, planning and the world's games, 1896-2012 (2nd ed.). Abingdon: Routledge Planning, History and Environment Series.

Cook, I. G., \& Murray, G. (2001). China's third revolution: Tensions in the transition to post-communism. Richmond: Curzon.

Dicken, P. (2004). Geographers and "globalisation" (yet) another missed boat? The Institute of British Geographers, 29, 5-26. doi:10.1111/j.0020-2754.2004.00111.x

Dong, L. (1985). Beijing: The development of a socialist capital, Chapter 2. In V. F. S. Sit (Ed.), Chinese cities: The growth of the metropolis since 1949. Oxford: Oxford University Press.

Gaulier, G., Lemoine, F., \& Ünal-Kesenci, D. (2007). China’s emergence and the reorganisation of trade flows in Asia. China Economic Review, 18, 209-243. doi:10.1016/j.chieco.2007.02.008

Gu, C., \& Cook, I. G. (2011). Beijing: Socialist capital and new world city, Chapter 4. In S. Hamnett, \& D. Forbes (Eds.), Asian cities: Risk and resilience. London: Routledge.

Guttal, S. (2007). Globalisation. Development in Practice, 17, 4-5, 523-531. doi:10.1080/09614520701469492

Held, D., McGrew, A., Globlatt, D., \& Perraton, J. (2002). Global transformations: Politics, economics and culture. Cambridge: Polity
Press.

Holscher, J., Marelli, E., \& Signorelli, M. (2010). China and India in the global economy. Economic Systems, 34, 212-217. doi:10.1016/j.ecosys.2010.02.002

Jia, C. (2012). Report: China biggest economy by 2030. China Daily, Business, 12 December.

Kelly, P. F. (1999). The geographies and politics of globalization. Progress in Human Geography, 23, 379-400. doi:10.1177/030913259902300303

Kirby, P. (2006). Theorizing globalization's social impact: Proposing the concept of vulnerability. Review of International Political Economy, 13, 632-655. doi:10.1080/09692290600839915

Li, C. (2001). China in 2000: A year of strategic rethinking. Asian Survey, 1, 71-90.

$\mathrm{Li}, \mathrm{J}$. (2010). Thousands to be removed for tech zone expansion. China Daily, 28 June.

Mackeras, C., \& Yorke, A. (1991). The Cambridge handbook of contemporary China. Cambridge: Cambridge University Press.

Munck, R. (2002). The globalization and labour: The new "great transformation”. London: Zed Books.

Parker, J. (1987). China's economy: The biggest developer of all. The Economist, 1 August, 3-22.

Saich, A. (1995). China's political structure, Chapter 3. In R. Benewick, \& P. Wingrove (Eds.), China in the 1990s. London: Macmillan.

Sanders, R. (2007). Introduction, Chapter 1. In R. Sanders, \& Y. Chen, (Eds.), China's post-reform economy-Achieving harmony, sustaining growth. London: Routledge.

Sapkota, J. B. (2011). Mainstreaming globalisation in poverty reduction strategy papers in the Asia-Pacific region. Development in Practice, 21, 999-1012. doi:10.1080/09614524.2011.591185

Sollinger, D. J. (1993). China's transition from socialism: Statist legacies and market reforms 1980-1990. London: M.E. Sharpe.

Temin, P. (1999). Globalization. Oxford Review of Economic Policy, 15, 76-89.

Wang, H., Zhao, C., Xiaokaiti, M., Zhou, Y., \& Zhao, R. (2012). Dual land market and rapid China's urbanization: Problems and solutions. Chinese Studies, 1, 1-4.

Williams, H. (2012). Globalization? It's as old as history itself. Think, 2, 24-27.

Wu, F. (2007). China's emerging cities: The making of new urbanism. London: Routledge.

Wu, W., \& Gaubatz, P. (2012). The Chinese city. London: Routledge.

Wu, F. (2001). China's recent urban development in the process of land and housing marketisation and economic globalization. Habitat International, 25, 273-289.

Wu, F., \& Webster, C. (2010). Marginalization in urban China: Comparative perspectives. Basingstoke: Macmillian.

Yusuf, S., \& Wu, W. (2002). Pathways to a world city: Shanghai rising in an era of globalization. Urban Studies, 39, 1213-1240.

Zhang, X., \& Zhang, K. H. (2003). How does globalization affect regional inequaklity within a developing country? Evidence from China. The Journal of Development Studies, 39, 47-67.

Zhang, J. (1991). Beijing's 20 year master plan. China Monitor, 12-14.

Zhang, L. (2008). Conceptualizing China's urbanization under reforms. Habitat International, 32, 452-470.

Zhang, L. (2001). The tiananmen papers. London: Little Brown.

Zhao, S., X. B., Chan, R. C. K., \& Sit, K. T. O. (2003). Globalization and the dominance of large cities in contemporary China. Cities, 20, 265-278. 